\title{
Superoxide dismutase phenotypes in duodenal ulcers: A genetic marker?
}

\author{
S. Sulekha, J. Madhavi, A. Venkateshwari, S. Yasmeen, N. Pratibha \\ Department of Genetics, Osmania University, Hyderabad - 500 007, India
}

BACKGROUND: Cu-Zn superoxide dismutases are antioxidative defensive enzymes that catalyze the reduction of superoxide anions to hydrogen peroxide.

AIM: The study focuses on the association of electromorph of superoxide dismutase with duodenal ulcers, which result due to an imbalance between aggressive and defensive factors.

MATERIALS AND METHODS: Endoscopically confirmed 210 duodenal ulcer patients and 185 healthy individuals for comparative analysis were considered for the present study. Phenotyping of superoxide dismutase was carried out by subjecting the RBC membranes to polyacrylamide gel electrophoresis, using appropriate staining protocols. RESULTS: Statistical analysis of SOD phenotypes revealed a significant increase of SOD $A^{\star} 2$ allele and Superoxide dismutases (SOD) 2-2 phenotype in duodenal ulcer group. Among these individuals, a predominance of Helicobacter pylori infection was observed. The increased preponderance of homozygotes can be explained on the basis of reduced and altered enzyme activity, which may lead to disturbance in homeostasis of antioxidant/oxidant culminating in high lipid peroxidative gastric mucosal tissue damage and ulceration. No variation in the distribution of SOD phenotypes with respect to Helicobacter pylori indicates the role of Mn-SOD rather than $\mathrm{Cu}-\mathrm{Zn}$ SOD in the Helicobacter pylori infected cases as reported earlier. CONCLUSIONS: Superoxide dismutase as a genetic marker / gene modifier, encoding for an antioxidant enzyme in maintaining tissue homeostasis of the gastric mucosa is discussed.

Key words: Antioxidant, duodenal ulcer, free radical, gene modifier, genetic marker, lipid peroxidation, superoxide dismutase

\section{Introduction}

Duodenal ulcers (DU) constituting the predominant form of peptic ulcers, found to occur in about $10 \%$ of the worldwide population, are characterized by the loss of mucosal resistance, as a result of action and interaction of several aggressive factors like Helicobacter pylori infection, acid, pepsin and other proteases secreted on one hand and several defensive factors like bicarbonate and antiprotease on the other hand. Oxidative stress also plays an important role in vascular physiology and pathology. ${ }^{[1]}$ Previous studies have shown that superoxide anion is produced by oxidases present in human vascular cells. ${ }^{[2]}$ However, net levels of oxidative stress are determined in parallel by production and biodegradation of free radicals as well as by genetic susceptibility. The major anti-oxidant systems in the mucosal vasculature include, catalase, glutathione peroxidase, thioredoxin and superoxide dismutases, which modulate the oxidative stress but the primary role in the metabolism of superoxide anion radical is exerted by superoxide dismutases. ${ }^{[2]}$

Superoxide dismutases (SOD) is well known for scavenging Superoxide radicals such as reactive oxygen species (ROS), subsequently protecting cells from oxidative injury and for maintaining tissue homeostasis. $S O D$ is polymorphic in nature with three identifiable phenotypes SOD $A^{*} 1$, SOD $A^{*} 2-1$ and SOD $A^{*} 2$ encoded by two allelic forms SOD $A^{*} 1$ and SOD $A^{*} 2$ respectively and inherited as co-dominant alleles. ${ }^{[3]}$ The gene is localized to $21 \mathrm{q} 21$-q22.1 region. ${ }^{[4]}$ Since no information with regard to SOD and its electromorph association is available with respect to duodenal ulcers, such a study is imperative to identify the role of susceptible marker and its associated allele, apart from its role as a modifier gene in the genetic etiology of duodenal ulcers. Therefore, the present study aims at identifying specific electromorph association of SOD in duodenal ulcers with respect to Helicobacter pylori and its possible role in the etiopathogenesis of duodenal ulcers. 


\section{Materials and Methods}

Blood samples from endoscopically confirmed cases comprising of 210 duodenal ulcers and 185 healthy controls matched for age and sex, were collected from Department of Gastroenterology, Osmania General Hospital, Hyderabad and voluntary blood donor camps, Hyderabad.

Five $\mathrm{ml}$ of venous blood was collected in EDTA to obtain red blood cell membrane. The whole blood was washed with normal saline thrice and then centrifuged with ice-cold water to obtain red cell membranes for the phenotyping of superoxide dismutase. The Helicobacter pylori infection status was tested by rapid urease test in mucosal tissue biopsies of the duodenal ulcers as described by Vaira et al. ${ }^{[5]}$

The phenotyping of SOD was based on Davies protocol[6] of an $8 \%$ polyacrylamide gel electrophoresis gel and the electrophoresis was carried out using 0.005 $\mathrm{M}$ tris glycine running buffer at $4^{\circ} \mathrm{C}$ for two hours at 20 $\mathrm{mA}$ constant current. The gel was then placed in a tray and incubated in freshly prepared staining solution which consisted of $5 \mathrm{ml}$ of phosphate buffer (pH 7.8), $8.5 \mathrm{ml}$ of riboflavin, $10 \mathrm{mg}$ of nitroblue tetrazolium chloride and $220 \mu$ of TEMED prepared in $50 \mathrm{ml}$ distilled water. Later, the gel was washed and transferred to distilled water and exposed under a bright fluorescent light till the background was blue and clear achromatic bands were visualized as cited by Beauchamp and Fridovich. ${ }^{[7]}$ Based on their mobility in the gel, the phenotypes of SOD A

Table 1: Frequency distribution of superoxide dismutase electromorphs in control and duodenal ulcer groups

\begin{tabular}{lcccc}
\hline SOD A* phenotype & \multicolumn{2}{c}{ Control } & \multicolumn{2}{c}{ Duodenal ulcers } \\
\hline $2-2$ & $\mathrm{nn}$ & $\%$ & & $\%$ \\
$2-1$ & 14 & 7.5 & 197 & 94.0 \\
$1-1$ & 160 & 86.5 & 8 & 4.0 \\
\hline Total & 11 & 6.0 & 5 & 2.0 \\
\hline
\end{tabular}

were identified as 2-2, 2-1 and 1-1, respectively.

Frequency distribution was computed and allelic frequencies of SOD phenotypes were estimated to test for the Hardy Weinberg equilibrium ${ }^{[8]}$ and odds ratio ( 2 x 2 contingency) at 95\% confidence interval limits was carried out to interpret the results statistically. ${ }^{[9]}$

\section{Results}

Table 1 shows the frequency distribution of superoxide dismutase electromorphs in control and disease groups wherein SOD 2-1 phenotypes were found to be predominant in normal individuals $(86 \%)$ while $2-2$ phenotypic individuals are at an increased risk to the disease condition (94\%).

The distribution of superoxide dismutase genotypic and allelic frequencies in control and duodenal ulcer groups is shown in Table 2. The frequency of SOD 2 and SOD 1 alleles were found to be 0.55 and 0.45 in healthy subjects and 0.96 and 0.04 in duodenal ulcer patients. A significant deviation from the HardyWeinberg equilibrium was observed in duodenal ulcer group strengthening the earlier observation [Table 1].

The odds ratio estimates of superoxide dismutase phenotypes in duodenal ulcer groups in comparison to control group, wherein an increased risk of SOD 2-2 phenotypic individuals to ulceration (log OR 5.6399) was observed, further strengthening the above observation [Table 3]. This could be attributed to SOD A*2 allele encoding for a less stable enzyme as a result of which altered scavenging of the superoxide free radicals may lead to oxidative stress induced mucosal damage, as seen in duodenal ulcers. Decreased activity of $\mathrm{Cu}-\mathrm{Zn} \mathrm{SOD}$ is also associated with initiation of nitric oxide ( $\mathrm{NO}^{-}$) mediated apoptotic cell death and hence tissue damage in ulcers groups. ${ }^{[10]}$

Table 4 shows the phenotypic distribution of SOD with respect to Helicobacter pylori status in control and

Table 2: Genotypic and allelic frequency distribution of superoxide dismutase in control and duodenal ulcer groups

\begin{tabular}{|c|c|c|c|c|c|}
\hline \multirow[t]{2}{*}{ SOD $A^{*}$ Alleles } & \multicolumn{2}{|c|}{ Allelic frequency } & \multicolumn{3}{|c|}{ Genotypic frequency } \\
\hline & Control & Duodenal ulcer & Types & Control & Duodenal ulcer \\
\hline $\operatorname{SOD} 2 \mathrm{~A}^{*}$ & 0.51 & 0.96 & $2-2$ & 0.26 & 0.92 \\
\hline SOD1A* & 0.49 & 0.04 & $\begin{array}{l}2-1 \\
1-1\end{array}$ & $\begin{array}{l}0.24 \\
0.50\end{array}$ & $\begin{array}{l}0.0018 \\
0.082\end{array}$ \\
\hline
\end{tabular}


Table 3: Odds test of association of SOD phenotypes in duodenal ulcers in comparison to control group

\begin{tabular}{|c|c|c|c|c|c|c|c|}
\hline \multicolumn{2}{|c|}{ SOD phenotypic comparisions } & \multirow{2}{*}{$\begin{array}{c}\text { Controls } \\
14\end{array}$} & \multirow{2}{*}{$\begin{array}{c}\text { Duodenal ulcers } \\
197\end{array}$} & \multirow{2}{*}{$\begin{array}{c}\text { Risk ratio } \\
19.6066\end{array}$} & \multirow{2}{*}{$\frac{\text { Odds ratio }}{281.4286^{*}}$} & \multirow{2}{*}{$\frac{\text { Log odds }}{5.6399^{*}}$} & \multirow{2}{*}{$\begin{array}{c}\text { 95\% Confidence interval } \\
115.1814 \text { to } 687.6287\end{array}$} \\
\hline $2-2$ vs $2-1$ & $2-2$ & & & & & & \\
\hline & $2-1$ & 160 & 8 & & & & \\
\hline & $1-1$ & 11 & 5 & & & & \\
\hline \multirow[t]{2}{*}{$2-1$ vs $1-1$} & $2-1$ & 160 & 8 & 0.1524 & 0.11 & -2.2073 & 0.030784 to 0.393062 \\
\hline & $1-1$ & 11 & 5 & & & & \\
\hline & Others & 171 & 13 & & & & \\
\hline \multirow[t]{2}{*}{$2-1$ vs others } & $2-1$ & 160 & 8 & 0.0535 & 0.0062 & & 0.002723 to 0.014116 \\
\hline & Others & 25 & 202 & & & & \\
\hline \multirow[t]{2}{*}{$1-1$ vs others } & $1-1$ & 22 & 5 & 0.5777 & 0.3858 & & 0.131505 to 1.131837 \\
\hline & Others & 174 & 205 & & & & \\
\hline
\end{tabular}

*Odds ratio $>1$ and lying between confidence interval with lower limit above 1 were taken as significant.

Table 4: Phenotypic distribution of superoxide dismutase with respect to Helicobacter pylori status in control and disease groups

\begin{tabular}{lcccccccc}
\hline SOD A $^{*}$ & \multicolumn{4}{c}{ Controls } & \multicolumn{3}{c}{ Duodenal } \\
\hline Phenotypes & HP+Ve & \multicolumn{2}{c}{ HP-Ve } & \multicolumn{2}{c}{ HP+Ve } & \multicolumn{2}{c}{ HP-Ve } \\
\hline & $\mathbf{n}$ & $\%$ & $\mathbf{n}$ & $\%$ & $\mathbf{n}$ & $\%$ & $\mathbf{n}$ & $\%$ \\
\hline $2-2$ & 10 & 32.2 & 1 & 1.3 & 175 & 93.0 & 22 & 100 \\
$2-1$ & 20 & 64.4 & 72 & 91.0 & 8 & 4.3 & & - \\
$1-1$ & 1 & 3.2 & 6 & 7.6 & 5 & 2.6 & - & - \\
\hline Total & 31 & 28.0 & 79 & 72.0 & 188 & 90.0 & 22 & 10.0 \\
\hline
\end{tabular}

disease patients. In general, an interesting observation made is the predominance of SOD 2-2 phenotype in $\mathrm{Hp}$ +ve healthy subjects and ulcer patients, but the nature of association cannot be demonstrated statistically as the frequency distribution of 2-1 and 1-1 phenotypes in $\mathrm{Hp}$-ve cases accounted to zero, further supporting the role of SOD as a gene modifier in such Helicobacter pylori infected cases. However, by observation, role of SOD $A^{*} 2$ allele scavenging the $\mathrm{O}^{2-}$ derived free radical released due to mucosal damage as a consequence of Helicobacter pylori infection further justifies the SOD as a genetic marker as well as modifier of the disease in such $\mathrm{Hp}+\mathrm{ve}$ cases. The study thus substantiates the role of SOD in the etiopathogenesis of duodenal ulcers and helps in genetic heterogeneity and risk prediction of duodenal ulcer groups.

\section{Discussion}

Cells have elaborated protective mechanisms to cope with potentially damaging molecules such as reactive oxygen species by synthesizing antioxidant enzymes. ${ }^{[10]}$ Superoxide dismutases (SOD) are key cellular defense systems that disproportionate $\mathrm{O}^{2-}$ into oxygen and $\mathrm{H}_{2} \mathrm{O}_{2}$, with the latter being detoxified by glutathione peroxidase or catalase. Cu-Zn SOD referred to as SOD 1 and $M n$ SOD as SOD 2 are the two eukaryotic SOD's. Cu-Zn SOD located in the cytosol, is expressed constitutively and is considered as a housekeeping enzyme; in contrast to $\mathrm{Mn}$ SOD which is located in the mitochondrion. The Cu-Zn SOD enzyme is a known polymorphic marker encoded by two allelic forms SOD $A^{*} 1$ and SOD $A^{*} 2$ and inherited as co dominant alleles. An increased risk of SOD 2-2 phenotypic individuals to ulceration (OR: $281.43^{*} \mathrm{Cl}: 115.18$ to 687.68 ) was observed, this could be explained on the basis of SOD $A^{*} 2$ allele contributing to decreased stability of the enzyme or lowered enzyme synthesis. Studies by Novak et $a^{[11]}$ revealed significant reduction in SOD activity and hence the locus might be 'regulatory' in nature wherein the altered structure and function of cell membranes especially of gastric mucosa as a result of ulceration, may have a key pathogenetic role in ulcers. SOD, a key enzyme in gastric mucosal protection, is depleted significantly in the ulcer edge compared to the controls and found to increase after healing with treatment. ${ }^{[12]}$ Hence, significant association of the SOD A*2 allele encoding for less stable enzyme, as a gene modifier in duodenal ulcers is justifiable.

Further, SOD A*2 allele contributing to less stable enzyme can have direct effect on lipid peroxidation and hence pathological progression of the disease. Significant elevation of malondialdehyde (MDA) in duodenal ulcers was reported which strengthens the 
oxidative stress mechanism associated with duodenal ulcers. ${ }^{[13]}$ Since MDA levels are negatively correlated any altered function of SOD enzyme may in turn lead to increased MDA levels, disrupting the homeostatic balance causing high lipid peroxidation of the membranes of gastric mucosa ${ }^{[14,15]}$ which may culminate to ulceration, due to depletion of SOD levels.

Previous studies suggest that only Mn-SOD plays an important role as an antioxidant against ROS and, sub-sequently, in the maintenance of cell turnover in gastric mucosa. ${ }^{[16]}$ Gotz et al have shown that gastric tissue of Helicobacter pylori positive individuals was higher in activity and content of the cytokine inducible Mn-SOD, with no change in the constitutive $\mathrm{Cu}-\mathrm{Zn}$ SOD. ${ }^{[17]}$ Hence Cu-Zn SOD role is rather trivial in case of Helicobacter pylori infection in duodenal ulcers. Our results are strengthened by the above observation implicating no association of Helicobacter pylori infection and $\mathrm{Cu}-\mathrm{Zn}$ SOD enzyme.

\section{Conclusion}

The study highlights a significant risk of homozygous SOD $A^{*} 2-2$ phenotypic individuals to duodenal ulcers and SOD $A^{*} 2$ allele encoding for a less stable enzyme may lead to decreased scavenging of $\mathrm{O}^{2-}$ radicals resulting in the oxidative stress induced gastric mucosal tissue damage and ulcerogenesis. Thus SOD may be considered as a genetic marker in genetic risk prediction and may have a direct or modifier role in ulcerogenesis and could help in delineating the genetic heterogeneity of duodenal ulcers.

\section{References}

1. Tandon R, Khanna HD, Dorababu M, Goel RK. Oxidative stress and antioxidants status in peptic ulcer and gastric carcinoma. Indian J Physiol Pharmacol 2004;48:115-8.

2. Fridovich I. Superoxide dismutases. Ann Rev Biochem 1975;44:147-59.
3. DeCroo S, Kamboh MI, Leppert M, Ferrell RE. Isoelectric focusing of superoxide dismutase: Report of the unique SOD $A^{*} 2$ allele in a US white population. Hum Hered 1988;38:1-7.

4. Huret JL, Delabar JM, Marlhens F, Aurias A, Nicole A, Berthier $\mathrm{M}$, et al. Down syndrome with duplication of a region of chromosome 21 containing the CuZn superoxide dismutase gene without detectable karyotypic abnormality. Hum Genet 1987;75:251-7.

5. Vaira D, Holtonb J, Menegattia M, Landia F, Riccia C, Ali $A$, et al. Blood tests in the management of Helicobacter pylori infection. Gut 1998;43:S39-46.

6. Davies BJ. Disc electrophoresis II. Method and application to human serum proteins. Ann N Y Acad Sci 1964;121:404-27.

7. Beauchamp C, Fridovich I. Superoxide dismutase: Improved assays and an assay applicable to acrylamide gels. Anal Biochem 1971;44:276-87.

8. Emery AE. Statistical Methods in Medical Genetics. Churchill Livingstone: UK; 1984.

9. Christensen R. Loglinear models and logistic regression. $2^{\text {nd }}$ ed. Springer-Verlag: New York; 1951.

10. Brockhaus F, Brune B. Overexpression of CuZn superoxide dismutase protects RAW 264.7 macrophages against nitric oxide cytotoxicity. Biochem J 1999;338:295-303.

11. Novak R, Bosze Z, Matkovics B, Fachet J. Gene affecting superoxide dismutase activity linked to the histocompatibility complex in $\mathrm{H}-2$ congenic mice. Science 1980;207:86-7.

12. Klinowski E, Broide E, Varsano R, Eshchar J, Scapa E. Superoxide dismutase activity in duodenal ulcer patients. Eur J Gastroenterol Hepatol 1996;8:1151-5.

13. Venkateshwari A, Prathibha N, Vidyasagar A, Pratap B, Murty JS. Malondialdehyde levels in patients with duodenal ulcer. Indian J Gastroenterol 1995;14:57-8.

14. Wang SH, Wang YZ, Zhang KY, Shen JH, Zhou HQ, Qiu $X Y$. Effect of superoxide dismutase and malondialdehyde metabolic changes on carcinogenesis of gastric carcinoma. World J Gastroenterol 2005;11:4305-10.

15. Zimmermann R, Flohe L, Weser U, Hartmann HJ. Inhibition of lipid peroxidation in isolated inner membrane of rat liver mitochondria by superoxide dismutase. FEBS Lett 1973;29:117-20.

16. Noguchi K, Kato K, Moriya T, Suzuki T, Saito M, Kikuchi $\mathrm{T}$, et al. Analysis of cell damage in Helicobacter pylori associated gastritis. Pathol Int 2002;52:110-8.

17. Gotz JM, Thiol JL, Verspaget HW, Offeerhaus GJ, Biemond I, Lamers CB, et al. Treatment of Helicobacter pylori infection favourably affects gastric mucosal superoxide dismutase. Gut 1997;40:591-6.

Source of Support: Financial support from Indian Council of Medical Research, New Delhi is kindly acknowledged,

Conflict of Interest: None declared. 